\title{
Genes encoding $\alpha$-amylase inhibitors are located in the short arms of chromosomes 3B, 3D and 6D of wheat (Triticum aestivum $\mathrm{L}$.)
}

\author{
R.Sanchez-Monge, D. Barber, E.Mendez F.García-Olmedo and G.Salcedo \\ Departamento de Bioquímica, E.T.S. Ingenieros Agrónomos, Ciudad Universitaria, E-28040 Madrid, Spain \\ Servicio de Endocrinología, Centro Ramón y Cajal, Carretera de Colmenar Km 9,100, E-28034 Madrid, Spain
}

Summary. Three $\alpha$-amylase inhibitors, designated Inh. I, II and III have been purified from the $70 \%$ ethanol extract of hexaploid wheat (Triticum aesivum L.) and characterized by amino acid analysis, $\mathrm{N}$-terminal amino acid sequencing and enzyme inhibition tests. Inhibitors I and III have identical $\mathrm{N}$-terminal sequences and inhibitory properties to those of the previously described $0.19 / 0.53$ group of dimeric inhibitors. Inhibitor II has an N-terminal sequence which is identical to that of the previously described 0.28 monomeric inhibitor, but differs from it in that in addition to being active against $\alpha$-amylase from Tenebrio molitor, it is also active against mammalian salivary and pancreatic $a$-amylases. Compensating nulli-tetrasomic and ditelosomic lines of wheat $\mathrm{cv}$. 'Chinese Spring' have been analysed by two-dimensional electrophoresis, under conditions in which there is no overlap of the inhibitors with other proteins, and the chromosomal locations of the genes encoding these inhibitors have been established: genes for Inh. I and Inh. III are in the short arms of chromosomes $3 B$ and $3 \mathrm{D}$, respectively, and that for Inh. II in the short arm of chromosome $6 \mathrm{D}$.

Key words: Wheat endosperm - $\alpha$-amylase inhibitors Gene mapping

\section{Introduction}

Protein inhibitors of $\alpha$-amylase were discovered in wheat endosperm over 40 years ago (Kneen and Sandstedt 1943). These inhibitors, which are active against insect and mammalian $\alpha$-amylases, but not against the cereal enzymes, have been thought to be relevant in the protection of this tissue and in relation to its nutritional properties (for reviews see Marshall 1975; Buonocore et al. 1977; García-Olmedo et al. 1982).

The inhibitors have been classified into three families: a $12 \mathrm{Kd}$ family of monomeric inhibitors, a $24 \mathrm{Kd}$ family of dimers and a high molecular weight $(60 \mathrm{Kd})$ family, formed by aggregates of $12 \mathrm{Kd}$ subunits (Deponte et al. 1976; Buonocore et al. 1977). The chemical and inhibitory properties of the first two types have been extensively studied (Silano et al. 1973, 1975, 1977, 1978; Petrucci et al. 1974, 1976; O'Connor and McGeeney 1981 and others) and. recently, the complete amino acid sequences of one inhibitor of the first type and two of the second type have been established (Kashlan and Richardson 1981; Maeda et al. 1983. 1985). Genetic studies concerning the chromosomal locations of genes encoding the different inhibitors have not been conclusive. Pace et al. (1978) compared the gel filtration patterns of $\alpha$-amylase inhibitors extracted from kernels of 11 of the 40 available compensating nullitetrasomic stocks of 'Chinese Spring' wheat. The analytical procedure used separated the three classes but could not distinguish between different inhibitors within each class. On the other hand, genetic studies carried out with crude albumin and globulin fractions that presumably included $\alpha$-amylase inhibitors did not include purification of individual components and tests of inhibitory activity (Noda and Tsunewaki 1972; Cubadda 1975; Aragoncillo et al. 1975; Fra-Mon et al. 1984).

We report here the purification and characterization of three $\alpha$-amylase inhibitors, and the chromosomal assignment of their corresponding genes.

\section{Materials and methods}

Biological materials

Milled endosperms from Triticum aestivum cv. 'Candeal' were used for the isolation of $\alpha$-amylase inhibitors. The complete series of nulli-tetrasomic from Triticum aestivum cv. 'Chinese Spring' (except those nullisomic for chromosome $2 \mathrm{~A}$ and $4 \mathrm{~A}$ ) 
and ditelosonic 3BL, 3DS and 6DS were the gift of E. R. Sears from the University of Missouri (Sears 1954, 1966).

\section{Sources of enzymes}

Trypsin, and $\alpha$-amylases from the mammalian pancreas, Aspergillus oryzae and barley were obtained from Sigma. Tenebrio molisor $\alpha$-amylase was prepared from larvae and the salivary $\alpha$-amylase from lyophilized crude saliva.

\section{Purification of a-amylase inhibitors}

Milled endosperm was delipidated with petroleum ether (bp $\left.50-70^{\circ} \mathrm{C} ; 10 \mathrm{v} / \mathrm{w} ; 1 \mathrm{~h}\right)$ and extracted twice with $70 \%(\mathrm{v} / \mathrm{v})$ ethanol $(10 \mathrm{v} / \mathrm{w} ; \mathrm{l} \mathrm{h})$. The solvent was rotoevaporated and the residue redisolved in $3 \mathrm{M}$ urea. dialyzed against $\mathrm{H}_{2} \mathrm{O}$ and freeze-dried. The ethanol extract was fractionated by gel filtration through Sephadex G-I00 as previously described (Rodriguez-Loperena et al. 1975). The fraction corresponding to the peak under $25 \mathrm{Kd}$ was further fractionated by ionexchange chromatography on carboxymethyl cellulose (CMcellulose; $50 \times 2.6 \mathrm{~cm}$ column), in $0.02 \mathrm{M} \mathrm{Na}$ acetate buffer ( $\mathrm{pH} 5.2$ ), with a linear gradient of 0.03 to $0.14 \mathrm{M} \mathrm{NaCl} . \alpha-$ Amylase inhibitor I was purified in a final step of high performance liquid chromatography (HPLC) on Vydac TP-RP (C18, particle size $10 \mu \mathrm{m}$, pore size $300 \mathrm{~nm}$, column size $250 \times 4.6 \mathrm{~mm}$ ) using a $20 \%-35 \%$ linear acetonitrile gradient.

\section{Two-dimensional gel electrophoresis}

Individual kernels of different genetic stocks were extracted with $70 \%$ ethanol according to Rodriguez-Loperena et al. (1975). The presence of the inhibitors under study in the different extracts was investigated by two dimensional electrophoresis: first dimension, isoelectrofocusing on preformed $\mathrm{pH}$ gradients ( $\mathrm{pH} 6-8 ; 5 \%$ polyacrylamide: $140 \times 2 \mathrm{~mm}$ column; $67 \mathrm{~V} \mathrm{~cm}^{-1} ; 7 \mathrm{~h}$; insertion at acid end); second dimension. starch-gel electrophoresis $(0.1 \mathrm{M}$ aluminium lactate buffer. pH 3.2, $3 \mathrm{M}$ urea: $28 \times 18 \times 0.1 \mathrm{~cm}$ slabs: $20 \mathrm{~V} \mathrm{~cm}^{-1} ; 4 \mathrm{~h}$ ). As a preliminary investigation. different $\mathrm{pH}$ gradients (4-9. 5-8. 6-8) and times $(2-7 \mathrm{~h})$ were tested for the 1st dimension. in order to obtain optimal separation of the three inhibitors.

\section{Amino acid analysis and protein sequencing}

Amino acid analysis and sequencing by automatic Edman degradation were performed essentially as previously reported (Lizaro et al. 1985).

\section{Inhibition tests}

Purified proteins were tested for $\alpha$-amylase-inhibitory activity by the method of Benfeld (1955), except that $0.02 \mathrm{M} \mathrm{Na}$ acetate, $0.1 \mathrm{M} \mathrm{NaCl}$, pH 5.4 buffer was used for Tenebrio molitor $\alpha$-amylase and $0.02 \mathrm{M} \mathrm{K}$ phosphate, $0.067 \mathrm{M} \mathrm{NaCl}$, $\mathrm{pH} 7.6$ buffer for pancreatic. Aspergillus oryzae and barley $\alpha$ amylases. All tests were carried out with approximately I unit of a-amylase (U.A.). defined as the amount of enzyme required to produce the reducing equivalents of $1 \mathrm{mg}$ of maltose in $10 \mathrm{~min}$. Inhibition of trypsin was tested following the procedure of Erlanger et al. (196l) as modified by Boisen and Djurtoft (1981).

\section{Results}

\section{Purification and identification of three $\alpha$-amylase inhibitors}

A $70 \%$ ethanol extract of the endosperm of the wheat cv. 'Candeal' was subjected to gel filtration under dissociating conditions and the peak under $25 \mathrm{Kd}$ was chromatographed in a column of CM-celtulose. Three fractions (I-III) with anti- $\alpha$-amylase activity were obtained (Fig. 1A). Fractions II and III were found to correspond to homogeneous proteins (here after Inh. II and Inh. III), both by two-dimensional electrophoresis and by HPLC (data not shown). Fraction I was a mixture of several components and was further fractionated by semi-preparative HPLC (Fig. I B). The homogeneous protein designated Inh. I was the active component of the mixture. Tests of the three protein against $\alpha$-amylases from human saliva and Tenebrio molitor are summarized in Table $I$. None of the three proteins showed inhibitory activity against, Aspergillus oryzae or barley $\alpha$-amylases, however Inh. II showed $27 \%$ inhibition of pancreatic $\alpha$-amylase at $20 \mu \mathrm{g} / \mathrm{U}$.A. No antitrypsin activity was found for any of the proteins, using a $10 \mu \mathrm{g} /$ assay.

In order to further characterize the three inhibitors, amino acid compositions and $\mathrm{N}$-terminal amino acid sequences were determined. Composition data are presented in Table 2 and the compositional divergence indexes for the binary comparisons of the three proteins with the three previously characterized inhibitors are presented in Table 3. N-terminal sequences are shown in Fig. 2. No heterogeneity was found at any of the sequenced positions.

\section{Chromosomal locations of genes encoding $\operatorname{Inh} . \mathrm{I}, \operatorname{lnh} . \mathrm{II}$ and Inh. III}

The two-dimensional electrophoretic procedure was optimized to achieve a minimum of overcrowding for the inhibitors. Best results were obtained for the pH 6-8 range in the first dimension. The chromosomes carrying genes for these proteins were identified by two-dimensional analysis of $70 \%$ ethanol extracts from compensating nulli-tetrasomics of wheat $\mathrm{cv}$. "Chinese Spring', and the chromosome arm was then investigated in the corresponding ditelosomics. The positions of the three inhibitors in the two-dimensional protein maps were ascertained by co-electrophoresis of the purified proteins with appropriate $70 \%$ ethanol extracts. The two-dimensional map of the wheat cv. "Chinese Spring' euploid is presented together with representative parts of maps corresponding to the critical genetic stocks in Fig. 3. The gene for Inh. I was found to be located in the short arm of chromosome 3B, that for Inh. III in the homoeologous arm of chromosome 3D. and that for Inh. II in the short arm of chromosome 6D. 

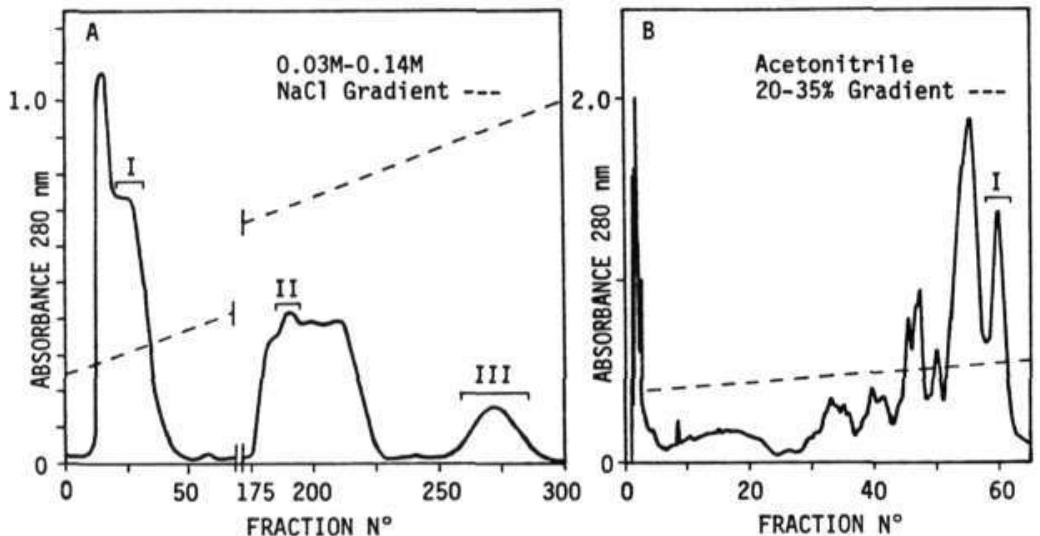

Fig. 1. A Fractionation of those protein components with a molecular weight under $25 \mathrm{Kd}$ in the $70 \%(\mathrm{v} / \mathrm{v})$ ethanol extract from wheat endosperm by ion-exchange chromatography on carboxymethyl cellulose with a linear gradient of $0.03-0.14 \mathrm{M} \mathrm{NaCl}$ in $0.02 \mathrm{M} \mathrm{Na}$ acetate buffer $(\mathrm{pH}$ $5.2)$. Fractions (I-III) with anti- $\alpha$-amylase activity are indicated. B Fraction I from A was subjected to high performance liquid chromatography on a Vydac TP-RP column using a $20 \%-35 \%$ linear acetonitrile gradient in a $0.1 \%$ trifluoroacetic buffer. The peak corresponding to homogeneous Inh. I is indicated
Inh. I SGPWM-CYPGQAF

Inh. III $S G P W M-C Y P G Q A F Q \vee P A L P A C R P L L R L Q C N$

Inh. II SGPWSWCDPATGYKVSALTG

Fig. 2. N-terminal amino acid sequences of Inh. I, Inh. II and Inh. III determined by automatic Edman degradation. The single-letter designations used are: $\mathrm{Ala}=\mathrm{A} ; \mathrm{Cys}=\mathrm{C} ; \mathrm{Asp}=\mathrm{D}$; Phe =F; Gly= G; His = H; Ile =I; Lys =K; Leu =L; Met =M; Asn $=\mathrm{N} ;$ Pro $=\mathrm{P} ; \mathrm{Gln}=\mathrm{Q} ; \operatorname{Arg}=\mathrm{R} ; \mathrm{Ser}=\mathrm{S} ; \mathrm{Thr}=\mathrm{T} ; \mathrm{Val}=\mathrm{V}$; $\operatorname{Tr} \mathrm{P}=\mathrm{W} ; \operatorname{Tyr}=\mathrm{Y}$

Table 1. Inhibitory activities against salivary and Tenebrio molitor $\alpha$-amylases of Inh. I, Inh. II and Inh. III

\begin{tabular}{lccc}
\hline Inhibitor & $\mu \mathrm{g} /$ U.A. ${ }^{a}$ & \multicolumn{2}{l}{$\%$ inhibition } \\
\cline { 3 - 4 } & & $\begin{array}{l}\text { Salivary } \\
\alpha \text {-amylase }\end{array}$ & $\begin{array}{l}\text { Tenebrio } \\
\alpha \text {-amylase }\end{array}$ \\
\hline I & 1 & 50 & - \\
& 5 & 100 & 85 \\
& 10 & - & 100 \\
II & 1 & - & 100 \\
& 10 & 80 & - \\
& 30 & 100 & - \\
III & 1 & - & 107 \\
& 5 & &
\end{tabular}

a U.A. $\equiv 1$ unit of $\alpha$-amylase (see "Materials and methods")

Fig. 3 A-J. Aneuploid analysis of genes encoding $\alpha$-amylase inhibitors, Inh. I, Inh. II and Inh. III of wheat. A Fractionation by combined electrofocusing ( $\mathrm{pH} 6-8) \times$ starch-gel electrophoresis ( $\mathrm{pH} 3.2$ ) of a $70 \%$ ethanol extract from T. aestivum cv. 'Chinese Spring'. B-J Pertinent zones of the two-dimensional maps of the indicated aneuploids. $\mathrm{n}=$ nulli; $\mathrm{t}=$ tetra; $\mathrm{dt}=$ ditelosomic. Maps $\mathbf{D}, \mathbf{G}$ and $\mathbf{J}$ correspond to a mixture of the indicated nulli-tetrasomics and $40 \mu \mathrm{g}$ of purified Inh. I, Inh. III and Inh. II, respectively. Arrows point to the positions of Inh. I-III; $-=$ absence and $+=$ presence of the corresponding inhibitor
A

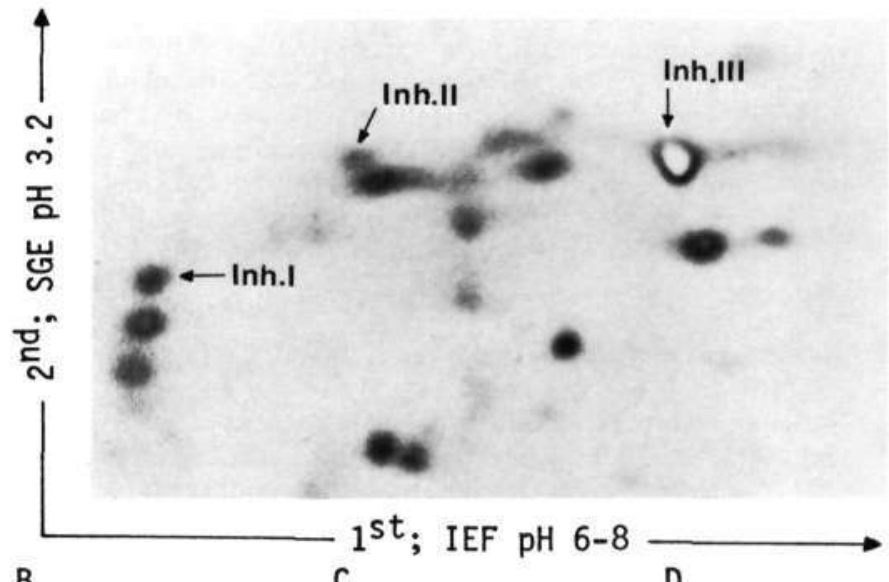

B

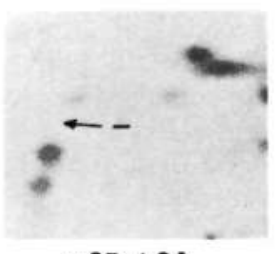

$n 3 B$ t3A

E

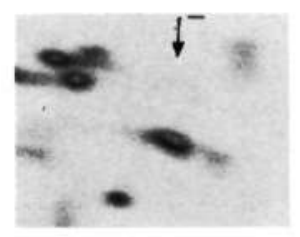

$n 3 D$ t3A

H

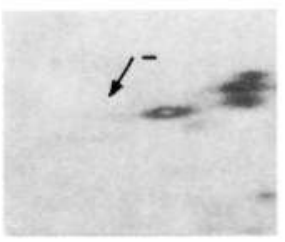

n6D t6B
C

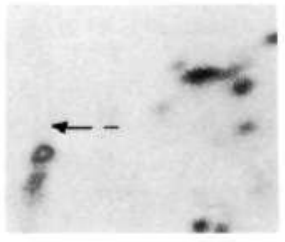

$\mathrm{dt} 3 \mathrm{BL}$

F

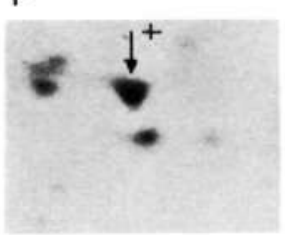

dt3DS

I

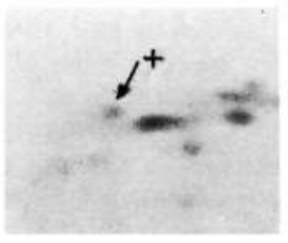

dt6DS

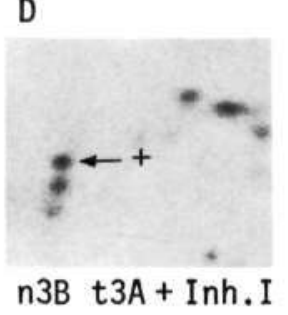

G

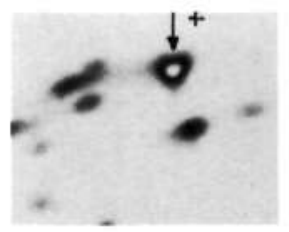

$n 3 D+3 A+$ Inh. II I

$\mathrm{J}$

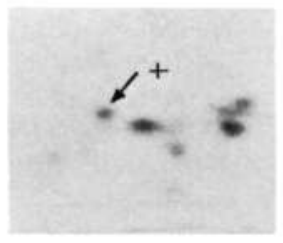

n6D t6B + Inh.II 
Table 2. Amino acid composition of inhibitors I, Il and III and their comparison with $\alpha$-amylase inhibitor $0.53,0.28$ and 0.19 . The amino acid composition data of $\alpha$-Amy inhibitor 0.53 and 0.19 have been deduced from the sequences in Maeda et al. (1985) and that of $\alpha$-Amy inhibitor 0.28 from its sequence as reported by Kashland and Richardson (1981)

\begin{tabular}{|c|c|c|c|c|c|c|}
\hline Amino acid & Inh. $1^{b}$ & Inh. 0.53 & Inh. II & Inh. 0.28 & Inh. III & Inh. 0.19 \\
\hline Lys & 5 & 4 & 5 & 6 & 3 & 3 \\
\hline His & 2 & 1 & 1 & 0 & 2 & 2 \\
\hline Arg & 6 & 6 & 7 & 7 & 8 & 8 \\
\hline As $x$ & 8 & 8 & 8 & 10 & 8 & 7 \\
\hline Thr & 4 & 3 & 3 & 3 & 4 & 3 \\
\hline Ser & 9 & 9 & 7 & 8 & 7 & 7 \\
\hline Glx & 14 & 12 & 16 & 12 & 14 & 13 \\
\hline Pro & 8 & 10 & 10 & 9 & 10 & 9 \\
\hline Gly & 12 & 11 & 11 & 11 & 10 & 10 \\
\hline Ala & 13 & 15 & 10 & 10 & 15 & 17 \\
\hline Val & 9 & 11 & 12 & 14 & 10 & 10 \\
\hline 1/2 Cys & 9 & 9 & 9 & 11 & 11 & 10 \\
\hline Met & 2 & 3 & 3 & 3 & 2 & 3 \\
\hline Ile & 3 & 3 & 3 & 2 & 3 & 3 \\
\hline Leu & 10 & 10 & 9 & 9 & 10 & 10 \\
\hline Tyr & 5 & 5 & 4 & 4 & 4 & 5 \\
\hline Phe & 3 & 2 & I & 0 & I & 2 \\
\hline No. of residues & 122 & 122 & 119 & 119 & 122 & $12 \overline{2}$ \\
\hline
\end{tabular}

ayptophan was not considered

- The experimental data has been adjusted to 122,119 and 122 for Inh. I. II and III, respectively

Table 3. Values of the compositional difference index for the binary comparisons of Inh. I, II and IIl with $\alpha$-Amy inhibitors $0.53,0.28$ and $0.19^{\circ}$

\begin{tabular}{llll}
\hline Inhibitors & I & II & III \\
\hline 0.53 & $\underline{0.21}$ & 0.53 & 0.23 \\
0.28 & 0.71 & $\underline{0.34}$ & 0.73 \\
0.19 & 0.39 & 0.77 & $\underline{0.11}$ \\
\hline
\end{tabular}

- The indexes has been calculated according to Cornish-Bowden (1980), as modified by Paz-Ares et al. (1983), using the data in Table 2

\section{Discussion}

We have obtained three different $\alpha$-amylase inhibitors in a homogeneous form as judged by two-dimensional electrophoresis and by $\mathrm{N}$-terminal sequencing. The $\mathrm{N}$-terminal sequences of Inh. I and Inh. III are identical and correspond to those previously published for the dimeric $(24 \mathrm{Kd})$ inhibitors, designated 0.19 and 0.53 (Maeda et al. 1985), whereas that of $\operatorname{lnh}$. II is identical with that of the previously reported monomeric $(12 \mathrm{Kd})$ inhibitor, designated 0.28 (Kashland and Richardson 1981). The compositional divergence indexes indicate that Inh. I is more closely related to 0.53 and Inh. III to 0.19 ; the low values of these indexes are compatible with complete identity but do not exclude differences at a few sequence positions. In the case of Inh. II, the only significant discrepancy with respect to 0.28 seems to be the possible presence in its sequence of $1 \mathrm{His}$ and $\mathbf{I P h e}$, which suggests that Inh. II is a different member of the same family.

Both Inh. I and Inh. III were active against the $\alpha$ amylases of Tenebrio molitor and mammalian saliva, as expected from inhibitors of the dimeric type (Bounocore et al. 1977). Neither inhibitor was active against pancreatic $\alpha$-amylase at the concentration tested (up to $40 \mu \mathrm{g} /$ U.A.), which means that, although the inhibitors may be active at higher concentrations, the salivary/ pancreatic activity ratio is greater than $10^{3}$. Maeda et al. (1985) have recently reported ratios of 90-500 for this type of inhibitors. Inh. III is $\mathbf{4 - 5}$ times more active than Inh. I against both the insect and the salivary enzyme, which is in line with the observations of Maeda et al. (1985) for 0.19 and 0.53 , and lends further support to the structural identification.

The data concerning Inh. II is more puzzling because although the structural information clearly indicates that this protein is either identical with or very closely related to the monomeric 0.28 inhibitor sequenced by Kashland and Richardson (1981), the inhibition specificity differs from that reported for that inhibitor: 0.28 is thought to inhibit only the insect enzyme. whereas Inh. II inhibits both the mammalian and the insect enzymes. The most plausible explanation 
is that we are dealing with a different member of the 0.28 family, with a different specificity. Indeed, a $12 \mathrm{Kd}$ inhibitor (size of the 0.28 type) with the same specificity of Inh. 11 has been detected in Aegilops speltoides by Bedetti et al. (1974). Furthermore, we have recently shown that among five related proteins of barley, there was a much closer relationship between a trypsin and an $\alpha$-amylase inhibitor than between two trypsin inhibitors (Barber et al. 1986).

The analysis of nulli-tetrasomic and ditelosomic stocks by two-dimensional electrophoresis has allowed the unambiguous assignment of genes encoding the closely related inhibitors of the dimeric type, Inh. I and Inh. III to homoeologous locations, in the short arms of chromosomes 3B and 3D, respectively, which further stresses their recent, common evolutionary origin. The gene for Inh. II has been similarly located in the short arm of chromosome $6 \mathrm{D}$, again in line with its inclusion in a separate structural family of inhibitors. Genes encoding proteins homologous to those reported here, active against $\alpha$-amylase or trypsin, or even inactive, have been located in chromosomes of homoeology groups 3, 4 and 7 of wheat or barley (Aragoncillo et al. 1975; Salcedo et al. 1984; Barber et al. 1986). The present finding indicates that this gene superfamily also extends to group 6. Several previous reports had assigned genes for albumins and globulins to chromosome groups 3 and 6 (for a review see Garcia-Olmedo et al. 1982), but no purification of individual components and functional or structural identification was carried out. According to their positions in the twodimensional map and the chromosomal location of their structural genes. Inh. I. Inh. II and Inh. III correspond to component numbers 12,8 and 11 in the two-dimensional map recently reported by us (Fra-Mon et al. 1984).

Acknowledgements. We acknowledge the gift of genetic stocks by E.R. Sears and the technical assistance of F. Soriano and 1. Garcia-Guijarro. This work has been supported by grant No. 2022/83 from Comisión Asesora de Investigación Cien. tifica y Técnica.

\section{References}

Aragoncillo C, Rodriguez-Loperena MA. Carbonero P, Garcia-Olmedo F (1975) Chromosomal control of nongliadin proteins from the $70 \%$ ethanol extract of wheat endosperm. Theor Appl Gene1 45:322-326

Barber D, Sanchez-Monge R. Mendez E, Lazaro A. GarcíaOtmedo F, Salcedo G (1986) New a-amylase and trypsin inhibitors among the CM-proteins of barley (Hordeum vulgare L.). Biochim Biophys Acta 869:115-118

Bedetti C. Bozzini A, Silano V, Vittozzi L (1974) Amylase protein inhibitors and the role of Aegilops species in polyploid wheat speciation. Biochim Biophys Acta 362: 299-307
Benfeld P (1975) Amylases, $\alpha$ and $\beta$. In: Colowick SP, Kaplan NO (eds) Method Enzymol. vol 1. Academic Press, New York. pp $149-158$

Boisen S. Djurtoft RD (1981) Trypsin inhibitor from rye endosperm: purification and properties. Cereal Chem 58: 194-198

Buonocore V. Petrucci T, Silano V (1977) Wheat protein inhibitors of $\alpha$-a mylase. Phytochemistry I6:8I1-820

Cornish-Bowden A (1980) Critical values for testing the significance of amino acid composition indexes. Anal Biochem 105:233-238

Cubadda R (1975) Chromosomal location of genes controlling the synthesis of some soluble proteins in $T$. durum and T. aestivum. In: Scarascia-Mugnozza GT (ed) Genetics and breeding of durum wheat. Library of the faculty of agriculture. Bari and Natl Inst Nutr, Roma, p 5

Deponte R. Parlamenti R. Petrucci T, Silano V, Tomasi M (1976) Albumin $\alpha$-amylase inhibitor families from wheat flour. Cereal Chem 53:805-820

Erlanger BF, Kokowsky N, Cohen $\mathrm{W}$ (1961) The preparation and properties of two new chromogenic substrates of trypsin. Arch Biochem Biophys 95:27I-278

Fra-Mon P, Salcedo G, Aragoncillo C, Garcia-Olmedo $F$ (1984) Chromosomal assignment of genes encoding saltsoluble proteins (albumins and globulins) in wheat and related species. Theor Appl Genet 69: 167-172

Garcia-Olmedo F, Carbonero P, Jones BL (1982) Chromosomal locations of genes that control wheat endosperm proteins. In: Advances in cereal science technol. AACC, St Paul Minn, pp 1-47

Kashlan N, Richardson M (198I) The complete amino acid sequence of a major wheat protein inhibitor of $\alpha$-amylase. Phytochemistry 20:1781-1784

Kneen E, Sandstedo RM (1943) An amylase inhibitor from certain cereals. J Am Chem Soc 65: 1247

Lazaro A, Barber D, Sakedo G, Mendez E. Garcia-Olmedo F (1985) Differential effects of high-iysine mutations on the accumulation of individual members of a group of proteins encoded by a disperse multigene family in the endosperm of barley (Hordeum vulgare L.). Eur J Biochem I49: $617-623$

Maeda K, Hase T. Matsubara $\mathbf{H}$ (1983) Complete amino acid sequence of an $\alpha$-amylase inhibitor in wheat kernel. Biochim Biophys Acta 743:52-57

Maeda K. Kakabayashi S. Matsubara H (1985) Complete amino acid sequence of an $\alpha$-amylase inhibitor in wheat kernel (0.19-inhibitor). Biochim Biophys Acta 828:213-221

Marshall JJ (1975) $\alpha$-Amylase inhibitor from plants. Am Chem Soc Symp Ser 15:244-266

Noda K, Tsunewaki K (1972) Analysis of seed proteins in ditelosomes of common wheat. Jpn J Genet 47:315-318

O'Connor CM. McGeeney KF (1981) Isolation and characterization of four inhibitors from wheat flour which display differencial inhibition specificities for human salivary and human pancreatic $a$-amylases. Biochim Biophys Acta 658 : $387-396$

Pace W, Parlamenti R, Rab A, Silano V, Vittozzi L (1978) Protein $a$-amylase inhibitors from wheat flour. Cereal Chem 55:244-254

Paz-Ares J, Ponz F. Aragoncillo C. Hemandez-Lucas C. Salcedo $G$, Carbonero $P$. Garcia-Olmedo $F(1983)$ In vivo and in vitro synthesis of CM-proteins (A-hordeins) from barley ( $\mathrm{Hor}$ deum vulgare L.). Planta 157:74-80

Petrucci T, Tomasi M, Cantagalli P, Silano V (1974) Comparison of wheat albumin inhibitors of $\alpha$-amylase and trypsin. Phytochemistry 13:2487-2495 
Petrucci T, Rab A, Tomasi M, Silano V (1976) Further characterization studies of the $\alpha$-amylase protein inhibitor of gel electrophoretic mobility 0.19 from the wheat kernel. Biochim Biophys Acta 420:288-297

Rodriguez-Loperena MA, Aragoncillo C, Carbonero P, Garcia-Olmedo F (1975) Heterogeneity of wheat endosperm proteolipids (CM proteins). Phytochemistry 14: $1219-1223$

Salcedo G, Fra-Mon P. Molina-Cano JL, Aragoncillo C, García-Olmedo F (1984) Genetics of CM-proleins (Ahordeins) in barley. Theor Appl Genet 68:53-59

Sears ER (1954) The aneuploids of common wheat. Mo Agric Exp Stn Res Bull 572:1-58

Sears ER (1966) Chromosome mapping with the aid of telocentrics. In: Mackey J (ed) Proc 2nd Int Wheat Genet Symp/Heredity (Suppl) 2:370-381
Silano V, Zahnley JC (1978) Association of Tenebrio molitor $\mathbf{L}$. $\alpha$-amylase with two protein inhibitor - one monomeric, one dimeric - from wheat fluor. Differential scanning calorimetric comparison of heat stabilities. Bicchim Biophys Acta 533:181-185

Silano V. Pochiari F, Kasarda DD (1973) Physical characterization of $\alpha$-amylase inhibitors from wheat. Biochim Biophys Acta 317: 139-148

Silano V, Furia M, Gianfreda L. Macri A. Palescandolo R, Rab A. Scardi V, Stella E, Valfre F (1975) Inhibition of amylases from different origins by albumins from the wheat kernel. Biochim Biophys Acta 391: 170-178

Silano V, Poerio E, Buonocore V (1977) A model for the interaction of wheat monomeric and dimeric protein inhibitors with $\alpha$-amylase. Mol Cell Biochem 18:87-91 